\title{
The Possibility of Urinary Tract Infection in Primary School Students with A Diagnosis of Febrile Pharyngotonsillitis
}

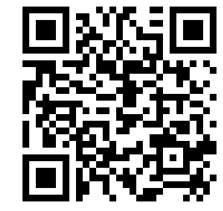

\author{
Che Sheng Huang ${ }^{1}$, Chyi Sen Wu${ }^{1}$, Ng Man Tsang ${ }^{2}$, Yu Cheng Liu ${ }^{1}$ and Wan Kong Sang*1,2 \\ ${ }^{1}$ Department of Pediatrics, Taipei city hospital, Renai branch, Taiwan \\ ${ }^{2}$ Lung Jiang Pediatric Clinic, Taiwan
}

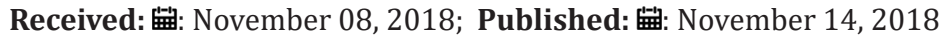

*Corresponding author: Kong Sang Wan, Department of Pediatrics, Taipei city hospital, Renai branch, Taiwan

\author{
Abstract \\ Background: Urinary tract infection (UTI) is one of the commonest bacterial infection seen in children, ranking second only to those of the \\ respiratory tract.
}

Material \& Methods: One hundred and five 6-12 years old school children with pharyngotonsillitis visit our outpatient clinic were recruited in this study. Urinalysis and mid-stream urine collection culture after disinfection of the private area were performed in all children. Serum procalcitonin, CRP and DMSA were performed in student with significant positive urine culture.

Results: The urine culture results showed positive rate in $48.6 \%$, negative rate in $39 \%$ and contamination urine culture was $12.4 \%$. Urinalysis did not indicate the possibility of positive urine culture. Also, the procalcitonin and CRP could not indicate upper UTI when compared with the results of DMSA.

Conclusion: This study indicates that urine tract evaluation is important and should be performed in children who are suspected with pharyngotonsillitis.

Keywords: UTI; Pharyngitis; Tonsillitis; E.Coli; Children

\section{Introduction}

Urinary tract infections are common in children. They may present with a range of severity form cystitis to febrile UTI or pyelonephritis. The presentation may be vague and have nonspecific symptoms. The younger the child is the more symptoms are atypical. Therefore, a UTI should be considered in all children with a fever and it is even possible associated with febrile pharyngotonsillitis [1,2]. In Scholer SJ study (1996) stated that an acute complaint of abdominal pain in children occurs in 5.1\% nonscheduled visits. Close follow-up will identify the $1 \%$ to $2 \%$ who proceeds to have a more serious disease process including UTI [3]. The clinical prediction rules for UTI was developed. Its sensitivity and specificity were 0.95 and 0.31 respectively if patient confirm to have 2 or more of the following 5 variables: less than 12 months old, white race, temperature of $39^{\circ} \mathrm{C}$ or higher, fever for 2 days or more, and absence of another source of fever on examination [4]. The gold standard for UTI diagnosis is significant colony counts of a single organism in urine obtained in a sterile manner. Positive urine culture was defined as 50,000 or more colony-forming units per milliliter of a urinary tract pathogen [5]. The most common uropathogens were E. coli, Pseudomonas aeruginosa, Klebsiella pneumoniae, and Proteus mirabilis [6].

However, children with Enterococcus species, Klebsiella species, and Pseudomonas aeruginosa were significantly less likely to exhibit pyuria, positive leukocyte esterase on dipstick urinalysis than children with [7]. Moreover, high prevalence of Staphylococcus saprophyticus is in patients $>10$ years and Proteus mirabilis is predominant in males [8]. Acute UTIs are relatively common in children, with $8 \%$ of girl and $2 \%$ of boys having at least one episode by seven years of age. Renal parenchymal defect are present in $3 \%$ to $15 \%$ of children within one to two years of their first diagnosed UTI. Evaluation of older children may depend on the clinical presentation and symptoms that toward a urinary 
source (leukocyte esterase or nitrite present on dipstick testing; pyuria of at least $10 \mathrm{WBC} / \mathrm{HPF}$ and bacteriuria on microscopy) [9]. Delay in treatment of febrile UTIs and permanent renal scarring are associated. In febrile children, clinicians should not delay testing for UTI.

\section{Material and Methods}

One hundred and five primary school children (Male $=47$, female=58) who were diagnosed with pharyngotonsillitis in outpatient clinic were involved in this study. Their common symptoms were fever, emesis, decreased appetite, sore throat, headache and abdominal pain. Urinalysis and mid-stream urine collection cultures were done in all participants. Serum procalcitonin, CRP and DMSA were also performed in students with significant positive urine culture 550,000 or more colony-forming units per milliliter of a single urinary tract pathogen).

\section{Results}

The urinalysis results including esterase, nitrite, proteinuria, occult blood, white blood cells and red blood cells were not significant, it cannot predict the possibility of urine culture. Culture of urine showed uropathgen positive rate $48.6 \%(n=51)$, negative rate $39 \%(n=41)$ and the contamination rate $12.4 \% \quad(n=13)$ respectively. was the only bacteria showed in culture. Also, the procalcitonin and CRP levels were mostly lower than their cutoff levels $(0.5 \mathrm{ng} / \mathrm{ml}$ and $20 \mathrm{mg} / \mathrm{L})$ respectively. Even the higher levels could not indicate upper UTI when compared with the results of DMSA.

\section{Discussion}

Twenty percent of febrile children have fever without an apparent source of infection after history and physical examination. Of these, a small proportion may have an occult bacterial infection, including bacteremia, UTI, occult pneumonia. Also, in children with fever without source, occult UTIs occur 3\% to $4 \%$ of boy younger than 1 year and $8 \%$ to $9 \%$ of girls younger than 2 years of age [10]. In this current study, the absolute number of WBCs or red blood cells in the urine and the presence of proteinuria, leukocyte esterase and nitrite were not associated with positive culture or urinary infection as proposed by Hooker JB (2014) study [11]. In review of literature, routine urinalysis had limited sensitivity, but moderate specificity, in predicting UTI in children. The composite urinalysis and moderate or large leukocyte esterase both had good negative predictive values for the outcome of UTI [12]. According to the procalcitonin, CRP against the results of acute-phase DMSA scan in children aged 0 to 18 years with culture confirmed episode of UTI, the cutoff values were used for the primary analysis of UTI: $0.5 \mathrm{mg} / \mathrm{mL}$ for procalcitonin, $20 \mathrm{mg} / \mathrm{L}$ for CRP [13]. Moreover, certain unopathogens: Enterococcus species, Klebsiella species, and Psiudomonas aeruginosa were less likely to exhibit pyuria $(>/=5$ WBCs per high power field or $>/=10 \mathrm{WBC}$ per cubic millimeter)
[14]. Therefore, the definitive diagnosis of UTI is based on the urine culture but clinicians should remember a higher contamination rate was found in the early stream (51\%) and midstream sample $(16 \%)$. The benefit of catching midstream urine samples for the diagnosis of UTI is most important $[15,16]$. In conclusion, collecting a viable urine sample for urine culture for diagnosis of UTI using clean voided methods in primary school students with fibril pharyngotonsillitis is feasible.

\section{References}

1. Santen SA, Altieri MF (2001) Pediatric urinary tract infection. Emerg Med Clin North Am 19(3): 675-690.

2. Iacobelli S, Bonsanie F, Guignard JP (2009) Urinary tract infection in children. Arch Pediatr. 18(7): 1073-1079.

3. Scholer SJ, Pituch K, Orr DP, Dittus RS (1996) Clinical outcomes of children with acute abdominal pain. Pediatrics 98(4): 680-685.

4. Gorelick MH, Shaw KN (2000) Clinical decision rule to identify febrile young girls at risk for urinary tract infection. Arch Pediatr Adolesc Med 154(4): 386-390.

5. Gorelick MH, Hoberman A, Kearney D, Wald E, Shaw KN (2003) Validation of a decision rule identifying febrile young girls at high risk for urinary tract infection. Pediatr Emerg Care 19(3): 162-164.

6. Alsammani MA, Ahmed MI, Abdelatif NF (2014) Bacterial uropathogens isolates and antibiograms in children under 5 years of age. Med Arch 68(4): 239-243.

7. Shaikh K, Shope TR, Hoberman A, Vigliotti A, Kurs Lasky M, et al. (2016) Association between uropathogen and pyuria. Pediatrics 138(1): e21060087.

8. Lo DS, Shieh HH, Ragazzi SL, Koch VH, Martinez MB, et al. (2013) Community-acquired urinary tract infection: age and gender-dependent etiology. J Bras Nefrol 35(2): 93-98.

9. White B (2011) Diagnosis and treatment of urinary tract infections in children. Am Fam Physician 83(4): 409-415.

10. Baraff LJ (2000) Management of fever without source in infants and children. Ann Emerg Med 36(6): 602-614.

11. Hooker JB, Mold JW, Kumar S (2014) Sterile pyuria in patients admitted to the hospital with infections outside of the urinary tract. J am Board Fam Med 27(1): 97-103.

12. Forster CS, Haslam DH, Jackson E, Goldstein SL (2017) Utility of a routine urinalysis in children who require clean intermittent catheterization. J Pediatr Urol 13(5): 488.

13. Shaikh N, Borrell JL, Evron J, Leeflang MM (2015) Procalcitonin, C-reactive protein, and erythrocyte sedimentation rate for the diagnosis of acute pyelonephritis in children. Cochrane Database Syst Rev 1: CD009185.

14. Shaikh N, Shope TR, Hoberman A, Vigliotti A, Kurs Lasky M, et al. (2016) Association between uropathogen and pyuria. Pediatrics 138(1): e20160087.

15. Ballouhey Q, Fourcade L, Couve Deacon E, Cros J, Lescure V, et al. (2016) Urine contamination in nontoilet-trained and uncircumcised boys. Urology 95: 171-174.

16. Miron D, Grossman Z (2009) The diagnosis and therapy of first community acquired urinary tract infection in children. Harefuah 148(11): 778-782. 


\section{ISSN: 2574-1241}

DOI: $10.26717 /$ BJSTR.2018.11.002037

Kong Sang Wan. Biomed J Sci \& Tech Res

(C) (i) This work is licensed under Creative

Submission Link: https://biomedres.us/submit-manuscript.php

$\begin{array}{ll}\text { BIOMEDICAL } & \text { Assets of Publishing with us } \\ \text { RESEARCHES } & \text { - Global archiving of articles } \\ & \text { - Immediate, unrestricted online access } \\ & \text { - Rigorous Peer Review Process } \\ \end{array}$

